\title{
Um trânsito baritado insólito
}

\author{
An unusual barium transit
}

Apresenta-se o caso de um homem, de 64 anos, com antecedentes de Diabetes Mellitus (DM) tipo 2 com mau controlo metabólico e aneurisma cerebral gigante da circulação posterior previamente intervencionado (colocados stents na artéria vertebral direita e na artéria basilar). No decurso da investigação de quadro de anorexia, vómitos, enfartamento pós-prandial e emagrecimento com 6 meses de evolução, foi equacionada a possibilidade de gastroparésia associada a neuropatia autonómica diabética e realizado estudo baritado esófago-gástrico. Na aquisição das imagens documentada aspiração silenciosa do contraste baritado para a árvore traqueobrônquica (Imagem 1 e 2). Realizada precocemente broncoscopia com aspiração de grande quantidade de bário. A confirmação da abolição do reflexo faríngeo e aparecimento de soluços persistentes levantou a suspeita de compressão nervosa ao nível do tronco cerebral; foi efetuada tomografia cerebral que mostrou trombose parcial do aneurisma da artéria basilar e aumento das suas dimensões com compressão do tronco cerebral (Imagem 3). Face à impossibilidade de correção do aneurisma foi colocada gastrostomia percutânea para alimentação. Como complicação da aspiração de bário, desenvolveu uma pneumonia com insuficiência respiratória grave que respondeu favoravelmente à antibioterapia. 0 quadro constitucional foi enquadrado na DM tipo 2 com mau controlo metabólico e provável neuropatia autonómica.

0 sulfato de bário é frequentemente usado como meio de contraste em estudos radiológicos, incluindo os estudos dinâmicos do trato gastrointestinal ${ }^{1}$. A aspiração de bário é uma situação rara mas potencialmente fatal (risco de insuficiência respiratória grave e infeção respiratória) ${ }^{2,3}$. As patologias que cursam com alterações da deglutição, como algumas doenças neurológicas e os tumores da cabeça e pescoço, associam-se a um maior risco de aspiração, e devem ser consideradas quando se pede um estudo com contraste baritado ${ }^{1}$. Não existem recomendações sobre o melhor tratamento embora se preconize a realização de broncoscopia sempre que há insuficiência respiratória ou se verifica aspiração de grande quantidade de contraste, na tentativa de aspirar o bário da árvore traqueobrônquica ${ }^{1,4}$. É ainda essencial tentar corrigir a causa que motivou a aspiração ou tomar medidas para as evitar. Embora as alterações radiográficas permaneçam durante muito tempo, raramente há dano pulmonar significativo (por exemplo fibrose) sendo o seu prognóstico a longo prazo favorável'.

\section{Bibliografia}

1. Tamm I, Kortsik C. Severe Barium Sulfate Aspiration into the Lung: Clinical Presentation, Prognosis and Therapy. Respiration. 1999; 66:81-84.

2. Fruchter O, Dragu R. A Deadly Examination. N Englan J Med.2003; 348:1016

3. Kaira K, Takise A, Goto T, Horie T, Mori M. Barium sulphate aspiration. Lancet. 2004; 364:2220

4. Gerada E, Gerada J. Accidental severe bronchial aspiration of barium uncovers diagnosis of bronchiectasis. Intern Emerg Med. 2013; 8:635-636.

\section{Diagnóstico: Aneurisma da artéria basilar com compressão do tronco cerebral}

\section{Marta Soares, Cristina Rosário}

Serviço de Medicina Interna. Hospital Pedro Hispano. Matosinhos. Portugal

Imagem 1. Estudo esófago-gástrico com aspiração de contraste de bário para a árvore traqueobrônquica (principalmente à esquerda)

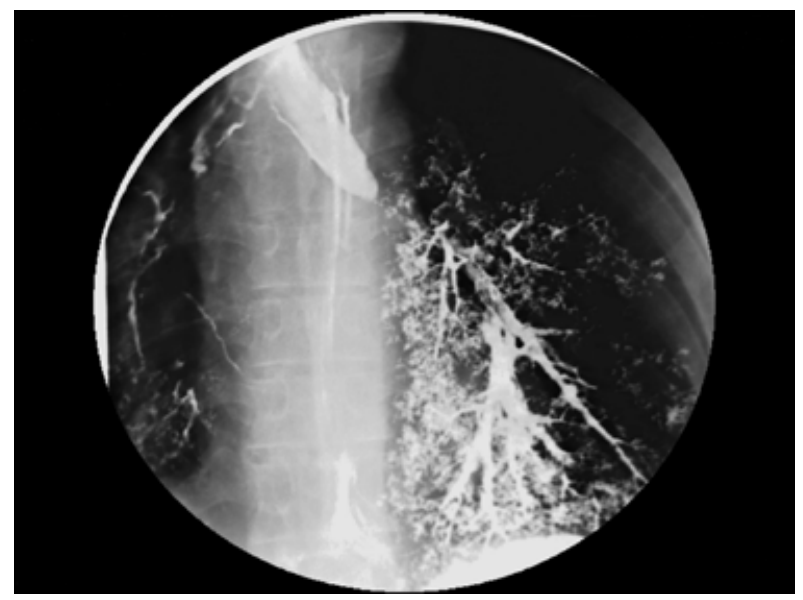

Imagem 2. Radiografia de tórax com os depósitos de bário localizados principalmente no pulmão esquerdo

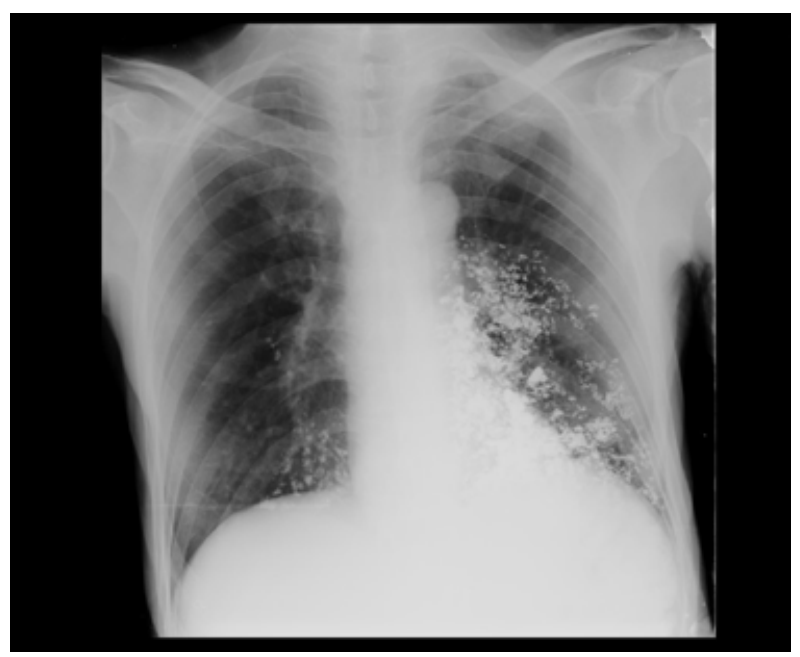

Imagem 3. Tomografia cerebral a mostrar dilatação aneurismática da artéria basilar em estreita relação com o tronco cerebral

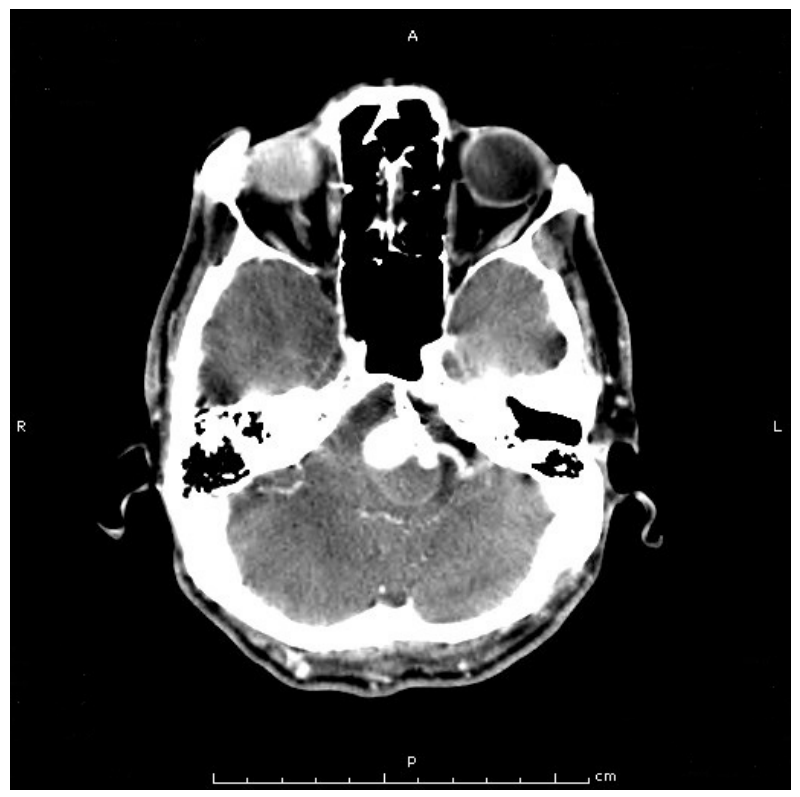

